\title{
Practical application of life-cycle management system for shore protection facilities
}

\author{
Hiroshi Yokota \\ Faculty of Engineering, Hokkaido University, Sapporo, Japan
}

\begin{abstract}
Shore protection facilities have a long lifetime and must be expected to meet demands for providing people living coastlines with safety and security. The principal demands for those facilities seem to be simple but have not been practically so easy to be kept over the requirements. The reasons for those are that facilities are rather big and are exposed to severe environments for materials. Those facts may cause difficulties in even visual inspection. In addition, as it would be very important, rise of the seawater level, etc. due to global warming may affect the function and performance, which has to be taken into account rehabilitation planning. To overcome such difficulties, it is important to pursue coordination between design and maintenance based on the procedure of the life-cycle management through which sustainability indicators would be maximum/minimum. This paper presents the concept and the framework of the life-cycle management system for those facilities and introduces methodologies of the management system particularly feasible to practical maintenance.
\end{abstract}

\section{KEYWORDS}

Shore protection facility; life-cycle management; performance degradation; function; requirements; inspection; evaluation; remedial action

\section{Introduction}

Social and economic activities concentrate in coastal areas in many countries. A shore protection facility is expected to prevent those areas from disasters caused by storm surge, tsunami, high waves, coastal erosion, etc. as well as to facilitate coast utilisation and environmental preservation. Typical structural types are embankment, revetment and parapet, detached breakwater, etc., an example of which is shown in Figure 1 (Japan Society of Civil Engineers [JSCE], 2000). While many facilities or structures have been newly built in coastal areas, some of them require remedial actions including repair, strengthening, upgrading or renovation because they have been exposed to very severe physical actions as well as harsh environmental actions. Physical actions such as waves and storm surges may cause damages to structures. In addition, materials tend to deteriorate rapidly in marine environments and degradation of structural performance or even structural collapse may be consequences.

At the initial design of a structure, designers make several assumptions, in which the most severe conditions are likely to be assumed for structural design in order to ensure structural performance over the requirement. Serious deterioration may be caused by insufficient durability design with optimistic assumptions against materials deterioration and by lack of proper maintenance after construction of the structure. To meet these facts, it is extremely important to pursue collaboration between the durability design work and subsequent maintenance work. Based on the performance-based design concept, structural performance should be ensured during the design service life. For this purpose, it is necessary to provide the methodologies to keep the structural performance over the minimum limits during the design and maintenance stages. In addition, even if no damages or deterioration occur, structures in coastal areas may have insufficient structural performance because of seawater level rise due to global warming, etc. The life-cycle management is a process which seeks to ensure that structural functions and performance would meet their requirements and that the service life of a structure would equal or exceed its design life, while taking into account the sustainability indicators such as life-cycle cost and environmental impact.

This paper firstly presents the concept and the framework of the life-cycle management system for shore protection facilities and structures. Then, simplified inspection strategy is proposed focusing on crack width induced in concrete members as one of the important management tools. Structural performance evaluation based on crack inspection is also described in this paper. Finally, remedial actions to meet upgrading structural performance requirements are discussed. These issues would be particularly feasible to practical maintenance for shore protection facilities and structures.

\section{Life-cycle management}

\section{Concept of life-cycle management}

The service life of a structure is made up of all the activities including planning, basic and detailed designs, execution including material selection, production and construction, maintenance including assessment and remedial action, and decommissioning. The life-cycle management (Yokota \& Hashimoto, 2013) is an integrated concept to assist in activities managing the total life cycle of structures to realise sustainability as shown in Figure 2. The International Federation for Structural Concrete (its name is well known FIB) defines the life-cycle management in its latest model code (FIB, 2010) as

the overall strategy to be used in managing a structure through its development and service life, with the aim of improving its efficiency from a business/engineering point of view, ensuring that it meets the associated performance requirements defined at the time of design or as may be subsequently modified during the service life of the structure.

During the initial design stage, the durability design will be applied to predict the performance degradation. While lots of alternatives can exist, the fundamental concept on how the structural performance should be ensured must be 


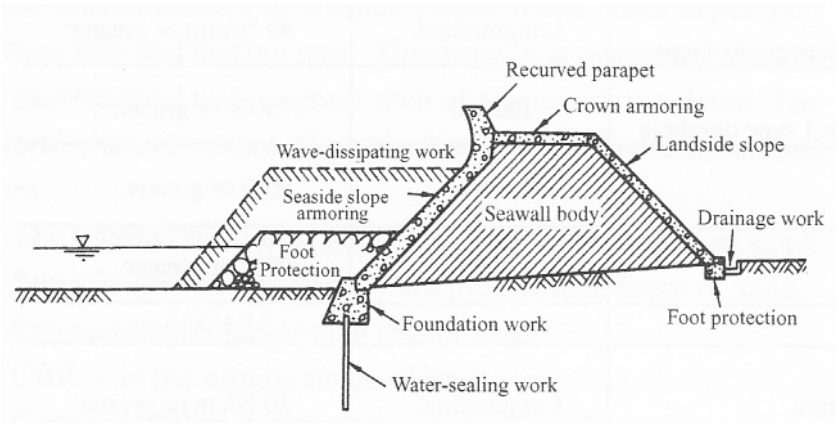

Figure 1. Typical cross section of embankment as an example of shore protection facilities and structures (JSCE, 2000).

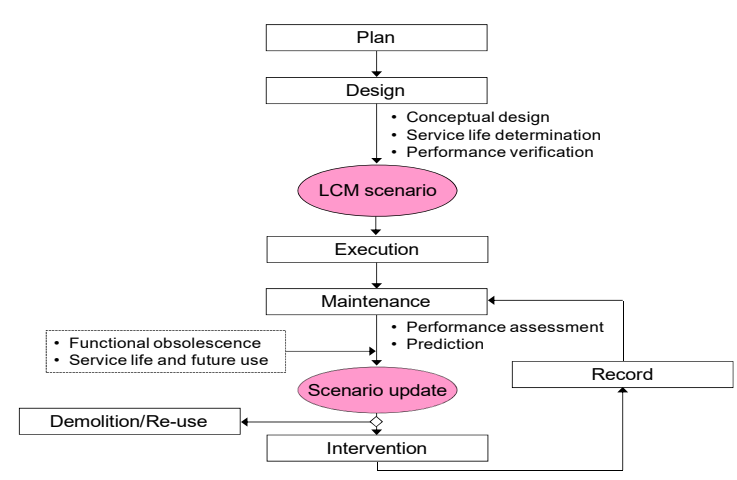

Figure 2. Life-cycle management system.

well considered based on conditions, design service life, structural characteristics, material properties, difficulties in assessment and remedial action, social and economic importance, etc.

Maintenance is the major strategy to counter the degradation, which is carried out to assess the present conditions of structure and to quantify the level of structural performance. In addition, by predicting the future progress of structural performance degradation, one should choose the most appropriate remedial action in which the decisionmake indicators are optimised under budget capping (Yokota, Iwanami, \& Kato, 2012). During the maintenance stage, maintenance engineers will initially follow the scenario ('LCM scenario' in Figure 2) that had been assumed at the design stage. In other words, the output of the design has to be verified with the maintenance work because progress of deterioration would not follow the design assumptions. This is related to 'Scenario update' in the figure. The LCM scenario should be updated with reflecting the actual situation of the structure and changes in conditions.

\section{Function and performance requirements}

Functions of a shore protection facility are principally to conserve coastal areas and protect the hinterland from high waves, storm surges, tsunami, etc. In addition, some facilities are required to preserve marine environments and ecosystem. To ensure those functions, it is important to ensure performance such as stability (safety), serviceability, environmental preservation, durability and restorability. The crest level of the facility is one of the performance indices that should be higher than the requirement level for

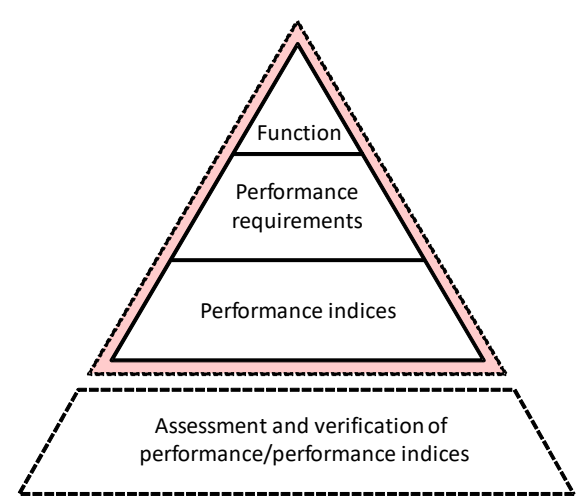

Figure 3. Function, performance requirements and performance indices.

ensuring stability or safety. Accordingly, the crest level of the facility is the easiest point to be designed and inspected. The hierarchy of the function, the performance requirements, and the performance indices is shown in Figure 3.

\section{Sustainability indicators}

To evaluate the LCM scenario, costs or life-cycle costs have been generally used as an indicator. The scenario having the lowest cost/life-cycle cost should be selected as the most appropriate scenario. However, from the viewpoint of sustainability, not only indicators of economic aspects but also indicators of social and environmental aspects should be considered in future. These indicators, as examples (ISO, 2015), should be determined in consideration of the following items:

- use of energy and material resources,

- emissions to air, water, and soil,

- production and management of wastes,

- species and ecosystem,

- landscape,

- community and territorial system, etc.

\section{Efficient method of assessment}

\section{Characteristics of cracks in un-reinforced concrete members}

While various kinds of structures have been constructed in coastal areas, the most popular structural type is reinforced concrete. Accordingly, the methodologies on structural performance evaluation on a deteriorated reinforced concrete structure have been intensively developed to date. 
In addition to reinforced concrete, un-reinforced concrete has been widely applied for coastal structures as parapet of seawalls, costal embankments, etc. However, it is not exaggerated to say that structural performance evaluation on un-reinforced concrete has been almost forgotten. Accurate, reliable evaluation on performance degradation of an un-reinforced concrete structure should be established soon because it has played important roles for shore protection.

Cracks in an un-reinforced concrete structure are the main symptom of deterioration; thus, crack widths, lengths, locations, and numbers of cracks are generally concentrated as one of the inspection items for regular maintenance of the structure. Moreover, the presence of a penetrating crack through the cross-section of a structure is one of the most concerns. A shore protection facility is rather long and large, and therefore unfortunately requires a lot of inspection work at the maintenance stage even only focusing on cracks.

Crack numbers, positions, widths and depths in many un-reinforced concrete parapets have been investigated (Furuya, Yokota, Komatsu, Hashimoto, \& Kato, 2014). Figure 4 shows the probability of vertical crack occurrence in parapets, which was analysed with the investigated data. The number of vertical cracks was distributed mostly between 0 (no cracks) and 2 regardless of the location and the dimensions of parapets. The data distribution seemed to follow the Poisson distribution as shown in Equation (1). Accordingly, the conformance degree of probability distributions of the numbers of vertical cracks to the Poisson distribution was estimated using the KolmogorovSmirnov statistic (Eadie, Drijard, James, Roos, \& Sadoulet, 1971):

$$
f_{p}(x)=\exp (-\mu) \frac{\mu^{x}}{x !}
$$

where $\mu$ is the mean number of cracks occurring a specified region (the Poisson parameter) and $x=0,1,2, \ldots$.

It was found that the Poisson distribution is a suitable distribution to describe the vertical crack numbers probability distributions. The mean value of vertical crack numbers in one span (between longitudinal construction joints) of the parapet was calculated 1.46. The probabilities of occurring at least one crack and two cracks are approximately 0.78 and 0.37 , respectively, as shown in Figure 4.

Herein, the maximum width of vertical cracks throughout the facility is focused because it seems that structural performance degradation of an un-reinforced concrete structure depends on the width of crack. The frequency distribution and the probability density functions of crack widths are shown in Figure 5, which were measured in two parapets of embankments: Facility C-1 and Facility S-1. The substructure type, overall length, and span length of $\mathrm{C}-1$ are a sheet pile type, 845 and $9.5 \mathrm{~m}$; and those of S-1 are a gravity type, 491 and $7.5 \mathrm{~m}$, respectively. The crack widths measured in coastal un-reinforced concrete structures were roughly distributed in the region of $2 \mathrm{~mm}$ or less as shown in Figure 5.

The distribution of crack width measured is discussed if it could be expressed with extreme statistics including the Gumbel, the Frechet, and the Weibull distributions. The relationship between the cumulative distribution function of each extreme distribution and the return period was quantified as shown in Equations (2-5), and eventually, the maximum crack widths were calculated.

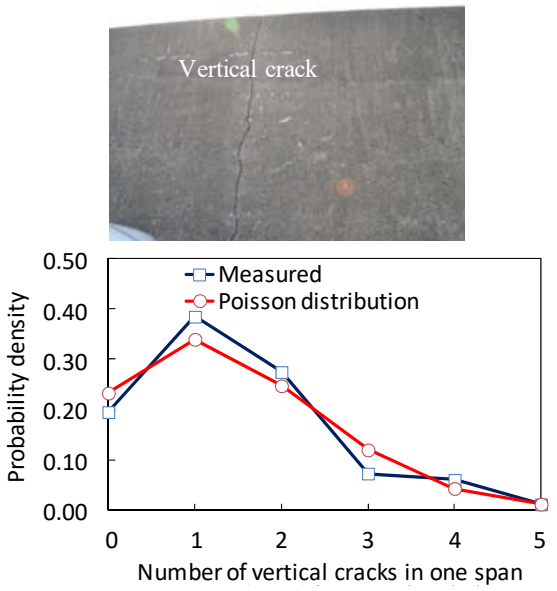

Figure 4. Probability of vertical crack occurrence in parapets

$$
\begin{gathered}
x_{g, \text { max }}=\alpha_{g}-\beta_{g} \cdot \ln \left[-\ln \left(\frac{T-1}{T}\right)\right] \\
x_{f, \text { max }}=\exp \left[\frac{1}{\alpha_{f}}\left[\ln \beta_{f}-\ln \left\{-\ln \left(\frac{T-1}{T}\right)\right\}\right]\right] \\
x_{w, \max }=\exp \left[\frac{1}{\alpha_{w}} \ln \left\{-\ln \left(\frac{1}{T}\right)\right\}+\ln \beta_{w}\right] \\
T=\frac{m \cdot L}{l}
\end{gathered}
$$

where $x_{\max }$ is the estimated maximum crack width, $\alpha$ and $\beta$ are distribution parameters, subscripts of these symbols $g$, $f$, and $w$ denote for the Gumbel, the Frechet and the Weibull distributions respectively, $T$ is the return period, $L$ is the total length of a facility, and $l$ and $m$ are the length and numbers of vertical cracks in the inspected area, respectively. The distribution parameters that showed most conformable to the distributed data (as shown in Figure 5) are summarised in Table 1.

The conformance degree of probability distribution on the extreme value analysis data to the Gumbel distribution, the Weibull distribution, and the Frechet distribution was evaluated with the Kolmogorov-Smirnov test as mentioned earlier. In conclusion (Furuya et al., 2014), it was found that the Gumbel distribution is the most suitable distribution to describe the extreme value analysis data.

\section{Estimation of maximum crack width with limited numbers of data}

Estimation of the maximum crack width of long coastal structures with partial measurements may contribute to energy-saving maintenance work. Certainly, in case that damage or deterioration may concentrate a certain part of facility due to longitudinal shapes in relation to the planar profile of coast lines, such the part may be selected for an inspection point. However, it is necessary to choose limited numbers of inspection points in case that almost uniform deterioration may occur.

The maximum crack width was estimated by the Gumbel distribution in Equation (2). Figure 6 illustrates the relationship between the sampling rate (the span numbers of 


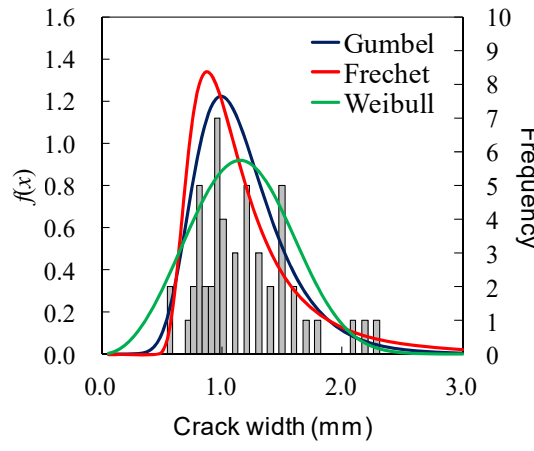

(a)

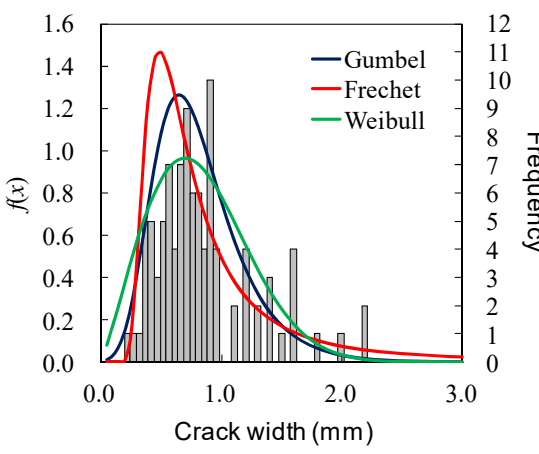

(b)

Figure 5. Frequency and probability density function of crack widths occurring in the spans of parapets. (a) Facility C-1. (b) Facility S-1.

Table 1. Parameters for extreme statistics analyses

\begin{tabular}{ccccccc}
\hline & \multicolumn{2}{c}{ Gumbel } & \multicolumn{2}{c}{ Frechet } & \multicolumn{2}{c}{ Weibull } \\
\cline { 2 - 7 } & $\alpha_{g}$ & $\beta_{g}$ & $\alpha_{f}$ & $\beta_{f}$ & $\alpha_{w}$ & $\beta_{w}$ \\
\hline S-1 & 0.648 & 0.291 & 2.113 & 0.321 & 2.148 & 0.935 \\
\hline C-1 & 0.987 & 0.300 & 3.290 & 0.823 & 3.065 & 1.303 \\
\hline
\end{tabular}

inspected area divided by the total span numbers) and the maximum crack width, where the maximum crack width obtained by the inspection of each facility is assumed as a true value. The estimated maximum crack widths approached the true value with an increase in the sampling rate. When the sampling rates become about 0.2 , the prediction error values converge with approximately 1.05 1.2. When the maximum crack width is estimated using extreme statistics, the extreme value analysis data can be fit to Gumbel distribution. It can be concluded that inspection on at least about $20 \%$ of the entire facility (the sampling rate is about 0.2 ) would give the most probable maximum crack width. In other words, the true maximum crack width would be obtained by the measured maximum crack width (the measured maximum crack width multiplied by $1.05-$ 1.2 ) with the minimum error.

\section{Effect of cracks on structural safety}

When a wide, deep crack occurs, safety that is one of the important structural performance requirements of shore protection facility may be more or less degraded. Based on the investigations by Furuya, Yokota, and Hashimoto (2012), the almost linear relationship has been found between crack width and crack depth with the correlation coefficient $(R)$ of 0.679 . If the crack depth can be estimated with easily measured physical parameters like crack width, it is very useful to evaluate structural performance. However, there is a concern how much the error of estimation might be.

The crack depth is increased as increase in not only crack width but also in the sizes of parapet. The influence of parapet sizes on the crack depth estimation is examined. The relationship between the product of the breadth of parapet and the crack width and crack depth is shown in Figure 7. The correlation coefficient was 0.863 . Accordingly, the crack depth can be reasonably estimated with crack width measured during inspection.

The structure analysis model of the parapet with one

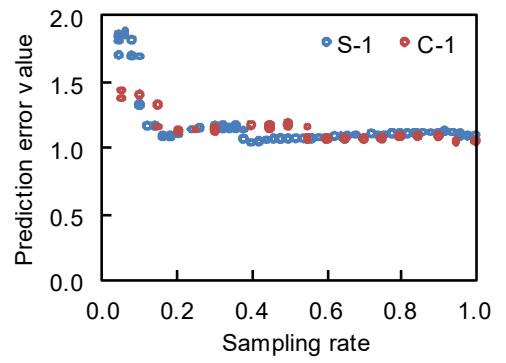

Figure 6. Relationship between sampling rate and prediction error value estimated by the Gumbel distribution.

vertical initial crack, as shown in Figure, 8 was prepared for nonlinear finite element analysis to calculate the loadcarrying capacity relating to the safety of structure. The analysis models depend on the depth, width, and the numbers of cracks. Vertical forces such as differential settlement and downward waves were applied as examples of external actions vertically applied. The smeared crack model was applied for the analysis.

The load-displacement curves are shown in Figure 9. The displacement in the figure is that parallel to the direction of force at the top centre of the model. The loaddisplacement curves of the parapet with initial cracks were almost linear before reaching the peak load regardless of the crack depth (width). After the peak load, failure progressed rapidly as smeared cracks occurred in the concrete. The peak load decrease began when the crack depth reached to $600 \mathrm{~mm}$. The peak load had $50 \%$ decreased in the 1000 mm-deep-case. Moreover, the stiffness, which is shown in the initial slope of load-displacement curve, had $7 \%$ decreased.

The estimated peak load is defined as the load-carrying capacity as structural performance. Since the crack depth can be calculated with the crack width using the relationship as shown in Figure 7, the relationship between the crack width and structural performance degradation is obtained. Being normalised with the structural performance of the parapet without initial cracks, structural performance degradation ratio is obtained. When horizontal forces such as wave forces were taken into account, the normalised structural performance of the parapet with an initial crack width of $7 \mathrm{~mm}$ was 0.96 . Under vertical forces such as settlement and uplift pressure application, the normalised structural performance decreases as the crack width is more than $4 \mathrm{~mm}$. It is considered that the influence of crack width on the structural performance of un-reinforced concrete 


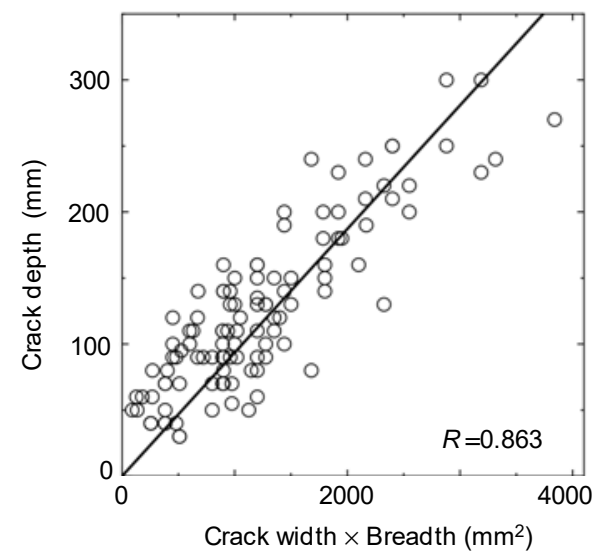

Figure 7. Relationship between parapet breadth $\times$ crack width and crack depth.

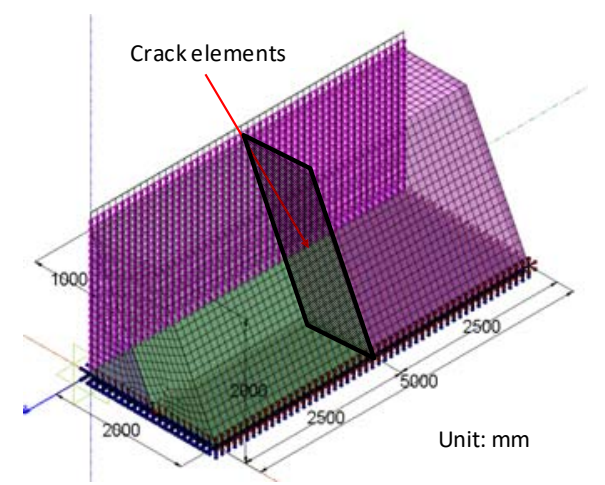

Figure 8. Structural analysis model of a parapet with a vertical crack in its midspan.

structures under vertical forces is more significant than in the case of horizontal forces. Therefore, when the condition grade of un-reinforced concrete structure is evaluated, it is necessary to consider the width and the number of cracks simultaneously.

It is concluded, from the viewpoint energy-saving inspection and performance evaluation with easily obtained inspection data, investigating crack widths in just about $20 \%$ of all the spans of an entire facility would give the maximum crack width with reasonable accuracy as described earlier. Since almost the linear relationship exists between crack width and crack depth in consideration of structure dimensions, performance evaluation of unreinforced concrete structure can be made based on the width and numbers of existing cracks. Such the trial enables us to execute more efficient maintenance work for shore protection facilities.

\section{Structural details for ensuring stability during earthquakes}

\section{Failure mechanism due to tsunami}

Lots of shore protection facilities in the Tohoku Region, Japan were partially or totally failed due to the earthquakerelated disasters caused by March 2011 Tohoku Region Pacific Coast Earthquake. The earthquake motion did not cause serious damages to the facility, but subsequent huge tsunami inflicted various catastrophic damages on them.

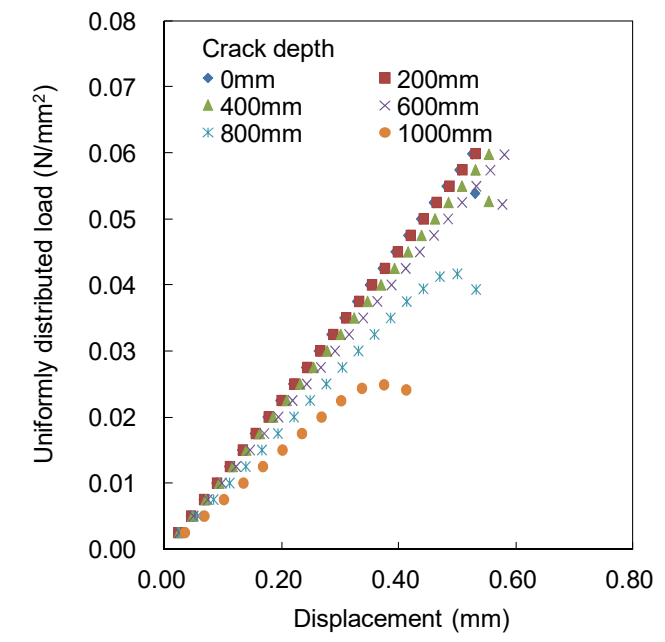

Figure 9. Load-displacement curves of un-reinforced concrete parapet with various cracks.

The failure modes of structures induced by subsequent tsunami can be categorised into the following five patters: (i) washout of entire structure, (ii) washout of covering concrete blocks, (iii) failure and/or washout of parapet, (iv) scouring and (v) movement due to seismic motions. Figure 10 (a) and (b) illustrates patterns (ii) and (iii), respectively (Ministry Land, Infrastructure, Transport and Tourism [MLIT], 2011a). MLIT (2011b) reported that the percentage of entirely collapsed coastal embankments would be reduced from $29 \%$ to $6 \%$ if rear toe had been well protected. The embankments in which toe of rear slope had been carefully strengthened was hard to reach entire washout. Moreover, the deeper the overflow water, the more failure percentage. When the overflow water depth was more than $4 \mathrm{~m}$, most of the structures entirely collapsed.

Figure 11 (a) depicts the typical failure progress of coastal embankments triggered by scouring at the toe of rear slope: (1) water stream of tsunami overtops the crest of the structure, (2) water travels down the rear slope to reach the ground at the toe of the slope with high speed, which causes scouring, (3) failure of rear slope cover and subsequent washout of backfill occur and then (4) washout of crest cover and further washout of backfill occur. The figure shows the upcoming wave case but the similar progress is expected in the backrush case.

Figure 11 (b) displays the typical failure progress of coastal embankments triggered by breakage of rear slope covering blocks: (1) water stream of tsunami overtops the crest of the structure, (2) high speed water stream washes out rear slope cover blocks and then (3) washout of crest cover and washout of backfill through the cover block joints. The other failure progress includes washout of concrete parapet due to tsunami (wave) forces.

\section{Countermeasures against tsunami causing progressive failures}

Lessons from the 2011 Tohoku Region Pacific Coast Earthquake suggest that already existing shore protection facilities may be required upgrades to meet such catastrophic tsunami actions. Almost all existing structures have been designed in consideration of likely tsunami having about 100-year return period. The structure should 


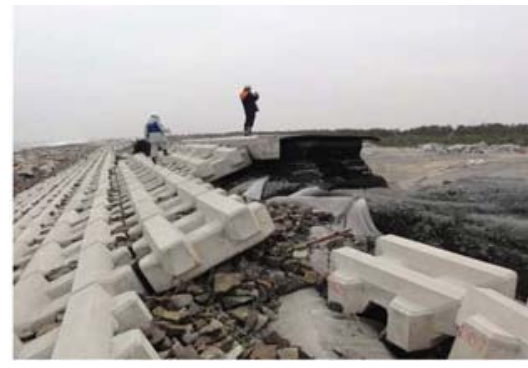

(a)

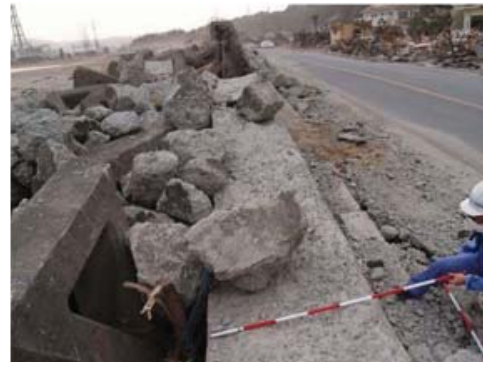

(b)

Figure 10. Typical failure of coastal embankments. (a) Washout of covering concrete blocks. (b) Washout of concrete parapets (MLIT, 2011a).

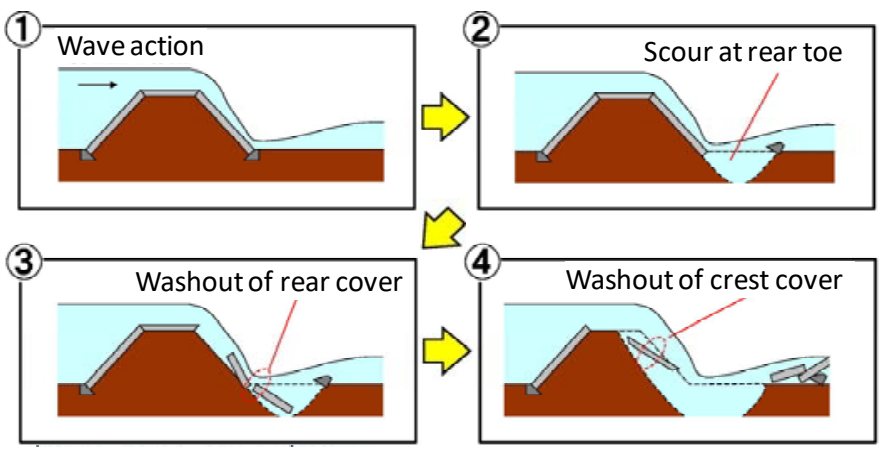

(a)

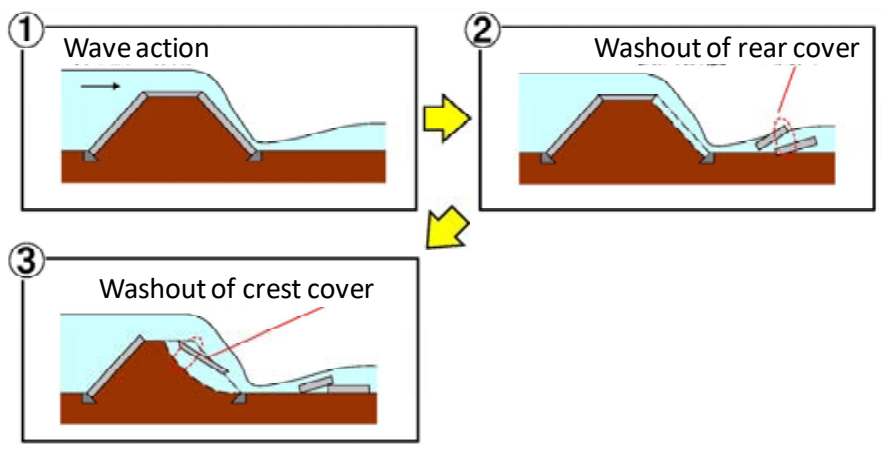

(b)

Figure 11. Typical failure progress of coastal embankment due to upcoming tsunami. (a) Triggered by scouring at the toe of rear slope. (b) Triggered by breakage of rear slope cover (MLIT, 2011b).

have enough ability to avoid progressive failure even when higher tsunami, say its return period of longer than several hundred years or more, than the design one attacks it. Structural robustness is such the ability to be realised by upgrading the existing structure. If the structure is designed to ensure structural robustness, it can keep its original cross section, which enables to reduce disaster in the hinterland. Also more time may be given for evacuation. Furthermore, remaining of even a part of structure enables to realise rapid restoration work and reduce the risk of subsequent failure leading to save restoration cost.

The following countermeasures are effective to ensure structural robustness for catastrophic tsunami: (1) to strengthen the toe of rear slope to avoid scouring, (2) to make front and rear slopes more gentle to reduce the speed of water down flow, (3) to thicken and strengthen covering concrete blocks, (4) to connect adjacent concrete blocks, (5) to remove concrete parapet and to raise earth fill to the crest level required, (6) to insert anchor bar between the parapet and the embankment, and so on.

\section{Sea level rise}

A shore protection facility has a long lifetime and must be expected to meet demands during its lifetime that cannot be foreseen. One of the concerns for shore protection facilities is likely sea level rise due to global warming (Intergovernmental Panel on Climate Change [IPCC], 2013). In addition, the IPCC indicates that the typhoon or storm intensity likely becomes high due to global warming as well. Accordingly, design tides and waves have to be determined in consideration of the above effects at the target year of performance verification. In other words, the levels of performance requirements tend to be high year by year. Kawai, Moriya, Mizutani, and Yokota (2012) proposed criteria for the determination of design values. 

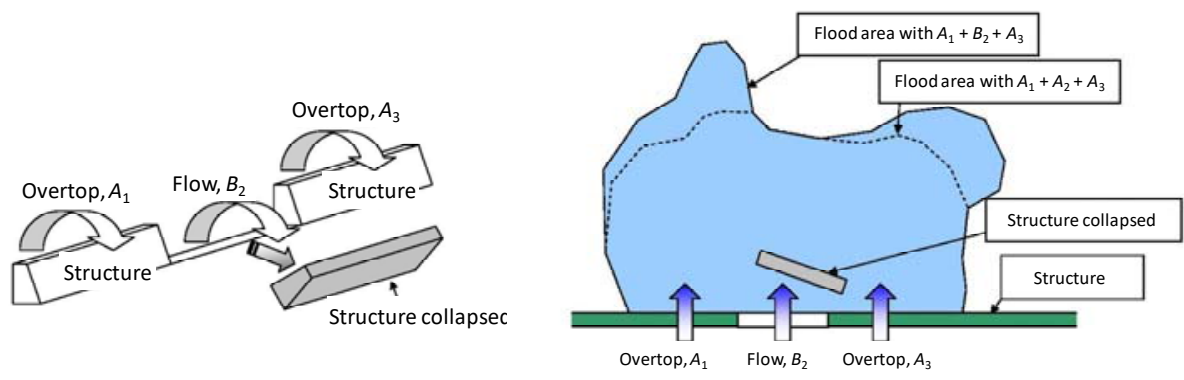

Figure 12. Partial collapse of a structure may bring flood in wider areas.

Table 2. Grading criteria based on the appearance of a shore protection facility (MAFF et al., 2014; originally in Japanese; translated by the author).

\begin{tabular}{lllll}
\hline Grade & \multicolumn{1}{c}{ a } & \multicolumn{1}{c}{ b } & c & Higher than the requirement \\
\hline Crest level & Lower than the requirement & - & - & Minute cracks (1 mm wide \\
Crack & $\begin{array}{l}\text { Penetrating cracks }(5 \mathrm{~mm} \\
\text { wide or more) }\end{array}$ & $\begin{array}{l}\text { Multi-directional, non- } \\
\text { penetrating cracks (several } \\
\text { millimetres wide) }\end{array}$ & $\begin{array}{l}\text { One-directional, non- } \\
\text { penetrating cracks (several } \\
\text { millimetres wide) }\end{array}$ & $\begin{array}{l}\text { or less) } \\
\text { No visible cracks }\end{array}$ \\
\hline $\begin{array}{l}\text { Damage/ } \\
\text { peeling }\end{array}$ & $\begin{array}{l}\text { Widely, deeply spreading } \\
\text { damage }\end{array}$ & Deeply spreading damage & Surface damage & $\begin{array}{l}\text { Small, local damages } \\
\text { No damages }\end{array}$ \\
\hline $\begin{array}{l}\text { Joint } \\
\text { Movement }\end{array}$ & $\begin{array}{l}\text { Overturn } \\
\text { Defect }\end{array}$ & $\begin{array}{l}\text { Widely opening joint } \\
\text { Percolation of water }\end{array}$ & $\begin{array}{l}\text { Gap } \\
\text { No water percolation }\end{array}$ & $\begin{array}{l}\text { Tiny unevenness } \\
\text { No opening, no unevenness }\end{array}$ \\
\hline
\end{tabular}

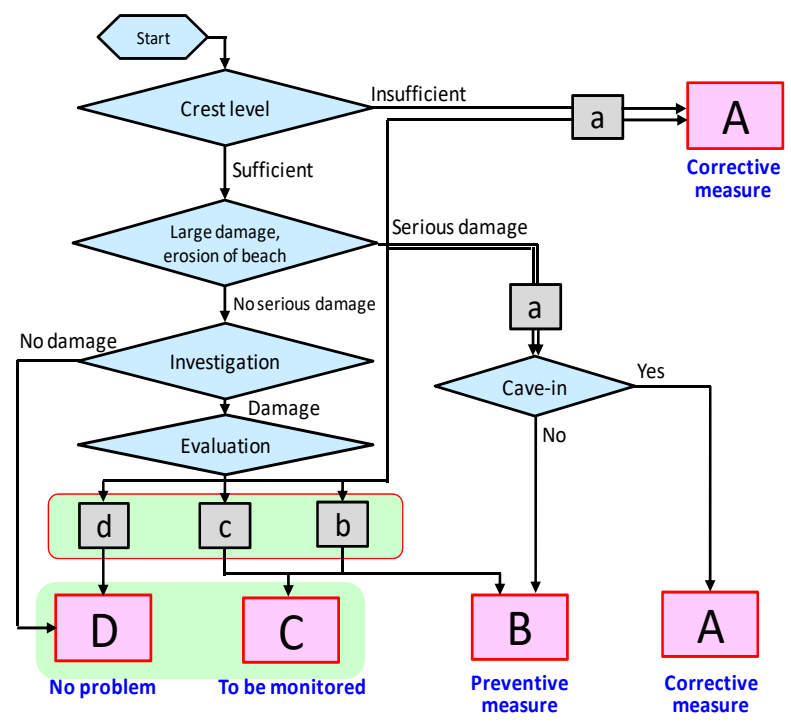

Figure 13. Decision-making flow with the grade evaluated through visual inspection (MAFF et al., 2014: originally in Japanese; translated by the author).

Another problem is that the effect of global warming should spread to all the existing facilities. It means that taking action on countermeasures to all the facilities would be impossible because of budget restrictions. Under such difficulties, proper levels should be determined from the viewpoint of the balance between soft and hard countermeasures. The hard countermeasure includes to heighten the crest level of facilities and/or to enlarge breadth of the facilities, while the soft countermeasure is to consider efficient ways of evacuation and/or warning to people living there. The process of determination of countermeasures for sea level rise and/or high intensity of typhoons/storms will be discussed later.
Proposed life-cycle management for shore protection facilities

The asset management is defined in PAS 55 (British Standards Institution [BSI], 2004) as 'systematic and coordinated activities and practices through which an organization optimally and sustainably manages its asset systems, their associated performance, risks and expenditure over their life cycles for the purpose of achieving its organizational strategic plan.' General maintenance work for a shore protection facility has focused on each structural component or even one facility. However, even if only limited parts of the facility fail, 


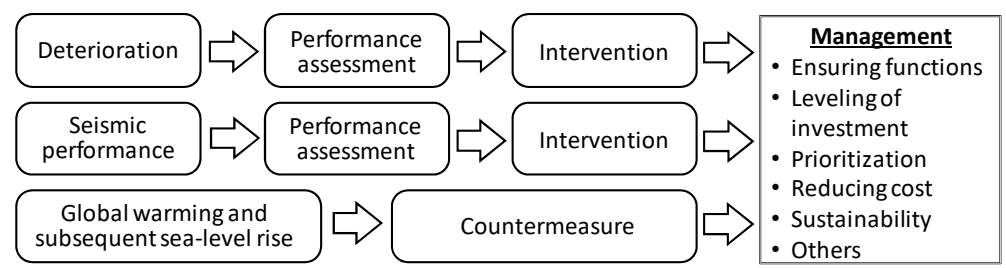

Figure 14. Life-cycle management for shore protection facilities from the viewpoints of deterioration, seismic performance, and environmental changes.

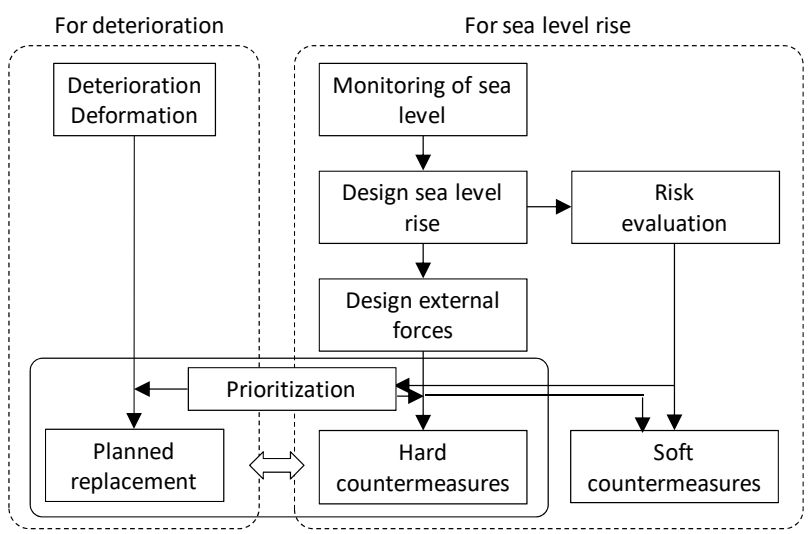

Figure 15. Procedure for determination of countermeasures for deterioration and for sea- level rise (CDIT, 2011; originally in Japanese; translated by the author).

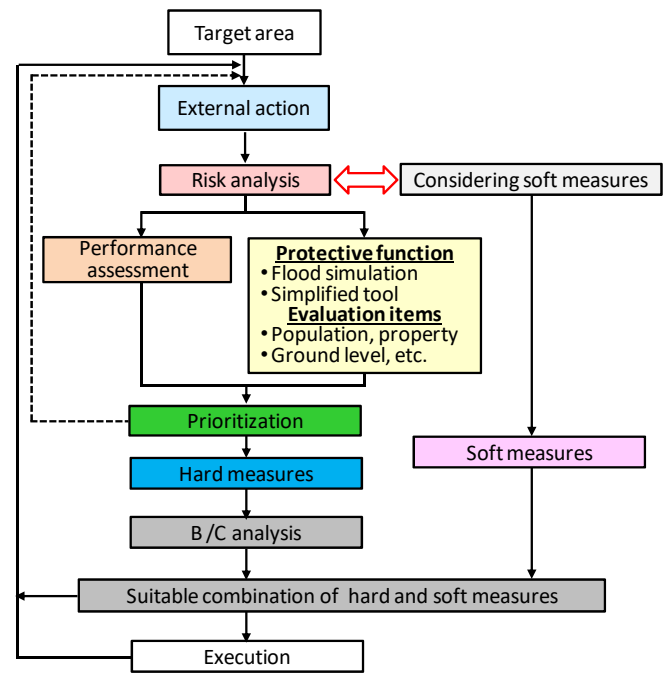

Figure 16. Procedure for making adaptation strategies for environmental changes (CDIT, 2011; originally in Japanese; translated by the author).

disaster may occur in wide areas as schematically shown in Figure 12. Accordingly, the life-cycle management for a shore protection facility should be extended to a group of facilities based on the concept of the asset management.

Shore protection facilities are built in harsh environments for materials and difficult to realise easy inspection. The regular inspection has been generally done for only limited parts of the facility and even some damages occurring in such limited area may not lead to entire collapse of the facility. The damage in the facility is generally initiated by excessive loads due to storms and earthquakes and propagated during the event of subsequent

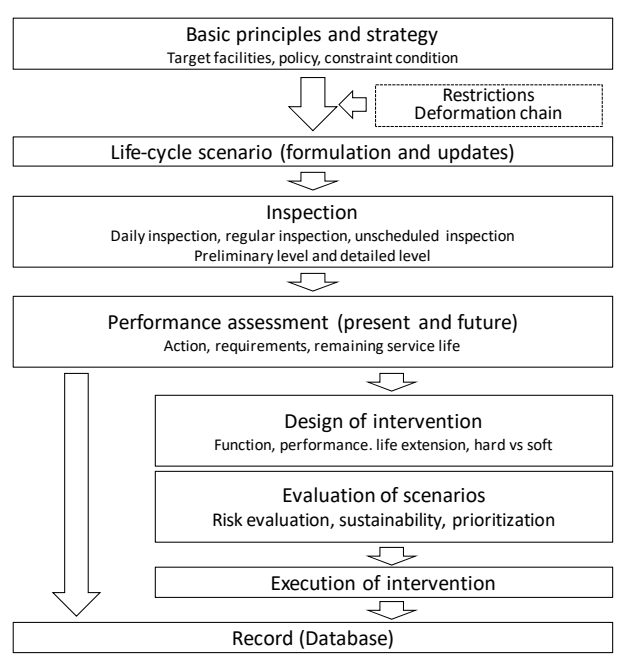

Figure 17. Concept of asset management of shore protection facilities in the near future.

wave actions, etc. According to the latest inspection manual for shore protection facilities (MAFF, Fisheries Agency, \& MLIT, 2014), structural performance evaluation is carried out mainly with visual inspection according to Table 2 .

The crest level, crack formation, damage/peeling of concrete, and joint movement between the adjacent spans are focused for the deterioration grade. If these grades can be associated with structural performance or capacity, it may be easy to evaluate and predict the current and future function and performance degradation. Though this association is difficult at the moment because of lack of data, in the meantime the decision-making flow is given, as 
presented in Figure 13, for counter action against likely performance degradation depending on the visually judged grade. By inputting the results of crack evaluation on unreinforced concrete member described in this paper, Table 2 can be updated more objectively. It is because crack widths specified in the table such as $5 \mathrm{~mm}$ wide and $1 \mathrm{~mm}$ wide do not have objective bases. When the analytical results, for example as shown in Figure 9, can be taken into account, the grading criteria can be updated with more accuracy and reliability. This makes to upgrade the evaluation process of a damaged structure; that is, to provide with definite bases during 'Evaluation' in Figure 13.

The life-cycle management should be done with understanding the characteristics of shore protection facilities on the basis of likely performance degradation caused by deterioration, upgrade in seismic performance due to higher tsunami and seismic motion, and sea-level rise due to global warming. To meet such demands, management should be effectively realised for seeking to achieve objectives shown in Figure 14. Against deterioration of a facility, the assessment of it can be done with some criteria as well as structural analyses. Future progress of performance degradation should be predicted as well. Based on these results, remedial action should be planned to ensure functions and performance over the requirements. On the other hand, against the sea level rise, the trend of the sea level is determined with doing monitoring, etc. and remedial actions should be planned.

Accordingly, the coordination of these remedial actions should be discussed. Figure 15 depicts the procedure for determinations of remedial actions for deterioration and for sea level rise. The best timings of each countermeasure are generally not the same; thus, prioritization between the two is well considered. Also, hard countermeasures and soft countermeasures should be well balanced as mentioned earlier. In particular, Figure 16 presents the procedure for adaptation strategy to meet future environmental changes such as sea-level rise and increase in external actions.

In conclusion, Figure 17 illustrates the proposed concept of asset management of shore protection facilities. Structural performance assessment and risk evaluation are particularly important both at present and in the future. Using proper sets of sustainability indicators, the most effective scenario should be selected and remedial action should be carried out.

\section{Conclusions}

Compared with other civil infrastructure such as bridges, methodologies and specific techniques for effective maintenance for shore protection facility are delayed in developing. We have a limited amount of time to find a reasonable way to upgrade the facility to meet likely sea level rise and catastrophic tsunami. More research and data collection of inspection are strongly expected. Once field data are accumulated with enough quantity and quality, the life-cycle management procedure can be improved more effectively and reasonably.

\section{Acknowledgments}

Dr. Katsufumi Hashimoto, Assistant Professor of Hokkaido
University, Dr. Ema Kato, Research Group Head of Port and Airport Research Institute, and Messrs. Koichi Furuya and Shuhei Komatsu, Ex-student of Hokkaido University are fully acknowledged for their great contributions on this research. The author thanks members of Working Group on Harbour and Coastal Structures in Special Committee on Great East Japan Earthquake, Japan Concrete Institute and JSCE Committee on Asset Management for Shore Protection Facility for beneficial discussion.

\section{Funding}

The part of this work was supported by JSPS KAKENHI Grant Number 24360174.

\section{References}

BSI. (2004). PAS 55: Asset management -- Part 1: Specification for the optimised management of physical infrastructure assets. London: Author.

CDIT. (2011). Manual for making adaptation strategies for sealevel rise considering the deterioration of coastal structures. Tokyo: Author.

Eadie, W.T., Drijard, D., James, F.E., Roos, M. \& Sadoulet, B. (1971). Statistical methods in experimental physics (pp.269271). Amsterdam: North-Holland.

FIB. (2010). fib Model code for concrete structures 2010. Berlin: Wilhelm Ernst \& Zohn

Furuya, K., Yokota, H. \& Hashimoto, K. (2012). Structural performance assessment of un-reinforced concrete coastal structures. Proceedings of the 1st International Conference on Performance-based and Life-cycle Structural Engineering, PLSE 2012, Hong Kong, 5-7 December 2012.

Furuya, K., Yokota, H., Komatsu, S., Hashimoto, K. \& Kato, E. (2014). Prediction of extreme crack width of concrete coastal facilities based on extreme statistics. Proceedings of 4th International Symposium on Life-Cycle Civil Engineering, IALCCE 2014, Tokyo, 16-19 November 2014.

IPCC. (2013). Summary for policymakers of the IPCC Report "Climate Change 2013 - The physical science basis". Cambridge: Cambridge University Press.

ISO. (2015). ISO/TS 21929-2: 2015 Sustainability in building construction - Sustainability indicators - Part 2: Framework for the development of indicators for civil engineering works. Geneva: Author.

JSCE. (2000). Design manual for coastal facilities 2000, Tokyo: Maruzen.

Kawai, H., Moriya, Y., Mizutani, N. \& Yokota, H. (2012). Discussion on future marine force criteria for life extension plan of coastal defence facility. Proceedings of Japan Society of Civil Engineers, B3, 68(2): 995-1000.

MLIT. (2011a). Committee material on countermeasures against tsunami in coast. Tokyo: Author.

MLIT. (2011b). Basic view on restoration of damaged coastal embankments etc. caused by 2011 Tohoku Region Pacific Coast Earthquake and tsunami. Tokyo: Author.

MAFF, Fisheries Agency, \& MLIT. (2014). Maintenance manual for coastal facilities. Tokyo: Ministry of Land, Infrastructure, Transport and Tourism.

Yokota, H., Iwanami, M. \& Kato, E. (2012). Strategic maintenance of infrastructure in coastal areas. Proceedings of International Symposium on Recent and Future Technologies in Coastal Development, Yokohama, 14-16 December 2012.

Yokota, H. \& Hashimoto, K. (2013). Life-cycle management of concrete structures. International Journal of Structural Engineering, 4, 138-145. 